\title{
Article Competition for Light Interception in Cotton Populations of
Different Densities
}

\author{
Huanxuan Chen ${ }^{1,2}{ }^{\mathbb{D}}$, Xinxin Zhao ${ }^{1,2}$, Yingchun Han ${ }^{2}$, Fangfang Xing ${ }^{2}$, Lu Feng ${ }^{1,2}$, Zhanbiao Wang ${ }^{1,2}$, \\ Guoping Wang ${ }^{2}$, Beifang Yang ${ }^{2}$, Yaping Lei ${ }^{2}$, Shiwu Xiong ${ }^{2}$, Xiaofei Li ${ }^{2}$, Minghua Xin ${ }^{2}$, Jie An ${ }^{2}$, Wenli Du ${ }^{2}$ \\ and Yabing $\mathrm{Li}^{1,2, *}$
}

check for updates

Citation: Chen, H.; Zhao, X.; Han, Y.; Xing, F.; Feng, L.; Wang, Z.; Wang, G.; Yang, B.; Lei, Y.; Xiong, S.; et al. Competition for Light Interception in Cotton Populations of Different Densities. Agronomy 2021, 11, 176. https://doi.org/10.3390/agronomy 11010176

Received: 14 December 2020

Accepted: 15 January 2021

Published: 18 January 2021

Publisher's Note: MDPI stays neutral with regard to jurisdictional claims in published maps and institutional affiliations.

Copyright: (c) 2021 by the authors. Licensee MDPI, Basel, Switzerland. This article is an open access article distributed under the terms and conditions of the Creative Commons Attribution (CC BY) license (https:// creativecommons.org/licenses/by/ $4.0 /)$.
1 Zhengzhou Research Base, State Key Laboratory of Cotton Biology, Zhengzhou University, Zhengzhou 450001, China; chenhuanxuan123@163.com (H.C.); zhaoxinx421@163.com (X.Z.); fenglucri@126.com (L.F.); wang_zhanbiao@126.com (Z.W.)

2 State Key Laboratory of Cotton Biology, Institute of Cotton Research of Chinese Academy of Agricultural Sciences, Anyang 455000, China; hyccky@163.com (Y.H.); xingyue530@163.com (F.X.); Zmswgp@126.com (G.W.); yangbf8002@163.com (B.Y.); lei200279@163.com (Y.L.); 18703673670@163.com (S.X.); lixiaofei01@caas.cn (X.L.); xinminghua985@126.com (M.X.); an60359542@163.com (J.A.); w1233216917@163.com (W.D.)

* Correspondence: liyabing@caas.cn; Tel.: +86-0372-256-2293

\begin{abstract}
Modification of the cotton canopy results in shade avoidance and competition for light, which shows that density and spatial arrangement of cotton have a great impact on light interception. This experiment was conducted in 2018 and 2019 in the experimental field at the Institute of Cotton Research of Chinese Academy of Agricultural Science in Anyang city, Henan Province, China. Six plant densities of cotton variety SCRC28 were used to assess spatial competition for light in cotton populations during the whole growing period. Light interception data were collected and analyzed according to the spatial grid method and the extension of Simpson's 3/8 rule. The results showed that at the bottom of the canopy, greater light interception was observed at high densities than at low densities, while in the external part of the layer of the canopy in the horizontal direction, low light interception was recorded at low densities. Leaf area, aboveground biomass and plant height were obviously correlated with light interception, and the cotton population with a higher density (8.7 plants $\mathrm{m}^{-2}$ ) performed best at the light interception competition, and with the highest yield. The results will provide guidance on light management through the optimization of the structure of the canopy to provide more solar radiation and a significant basis by which to improve the management of light and canopy architecture.
\end{abstract}

Keywords: light interception; cotton; plant density; spatial distribution

\section{Introduction}

Cotton (Gossypium hirsutum L.) is an important cash crop in China [1] and plays a role in national defense, medicine, and industry [2]. However, as China's total arable land area decreases each year [3], the competition between grain and cotton is increasing, and cotton production decreases each year. Keeping the total area of cotton cultivation unchanged or slightly reduced while achieving an increase in total cotton production and cotton yield requires understanding of light competition among plants. Traditional cotton planting technology is inefficient because labor costs are high and operation processes are cumbersome, and rapid development of the cotton industry is not applicable [4], hindering cotton production [5]. To solve these problems, a highly productive agricultural production system is needed that combines maximum resource utilization with automation provided by agricultural machinery [6]. Cotton is a crop with indeterminate growth habit, and lighting is a key factor that can directly and indirectly determine its quality and yield $[7,8]$.

Photosynthetically active radiation (PAR) at wavelengths of $400-700 \mathrm{~nm}$ is used in photosynthesis by green plants [9-11]. It is important to identify the characteristics of 
light interception that improve the potential photosynthetic activity of green plants [12,13], as high efficiency in the absorption and conversion of PAR can affect crop biomass and improve crop economic yield [14].

Cotton is a species that is suitable for growth in high-light conditions [7]. The duration of sunlight has a direct impact on growth and development, and lack of light directly affects the structure of cotton stems and leaves and the flowering time. Studies have shown that cotton yields are affected by the total amount of solar radiation that is intercepted by cotton and radiation use efficiency (RUE) [15]. The amount of light intercepted by cotton is influenced by factors such as cotton canopy structure, while RUE is influenced by factors such as photosynthetic characteristics of different varieties and the environmental conditions during cultivation [16].

Density can be increased by using narrow rows [17]. Densities and spatial arrangement of cotton plants have a great impact on light interception because modification of the cotton canopy results in shade avoidance and competition for light. A number of studies have shown that the leaf area index (LAI) and canopy structure affect the accumulation of intercepted PAR [18-21]. The architecture of the cotton canopy has significant influence on the photosynthetic process and the ability of light to enter the canopy [22]. In cotton plants, the canopy is directly linked to leaf shape and structure, and directly affects light interception and overall yield, while the LAI determines the interception of solar radiation and light capture efficiency [23]. Previous studies have shown that the relationships between canopy structure and light interception can be measured by using different methods. Zhi's study showed that the cotton canopy structure affected the spatial distribution of PAR, which was highly correlated with LAI and biomass [24].

A variety of plant models have been developed and used to describe the relationships between different plant growth. The 3-D virtual plant model, also called the functionalstructural plant model, has been used to describe the physiological processes involved in plant growth, such as the coordination of organ expansion dynamics and geometric variables [25]. Herve Rey [26] presented a method to build a 3-D virtual flower model by using AMAP and MMR software and simulated light interception during different periods of growth and for different organs of the plant. Gu's study [27] involved designing a functional-structural plant model named CottonXL to simulate the growth of cotton leaves and fruits and showed good accuracy in simulating the LAI. This model was used by Mao to estimate light interception by cotton in two growing systems and to determine row distance and plant densities [28].

This present study was carried out to identify the spatial distribution of light interception in cotton populations of different densities throughout the whole growing period, with a particular aim to evaluate (i) the trends of and differences in canopy light interception by these cotton populations during the process of cotton growth and (ii) the changes in LAI and aboveground biomass with canopy light interception among these cotton populations. The results provide guidance on light management of cotton through the optimization of canopy structure to increase plant acquisition of solar radiation.

\section{Materials and Methods}

\subsection{Experimental Site}

The experiment was conducted in 2018 and 2019 in an experimental field at the Institute of Cotton Research of the Chinese Academy of Agricultural Science in Anyang city, Henan Province, China $\left(36^{\circ} 06^{\prime} \mathrm{N}, 114^{\circ} 21^{\prime} \mathrm{E}\right)$. The experimental field is a long-term cotton cropping field with medium loam soil and total N, P, and K contents in the $0-40 \mathrm{~cm}$ layer of $0.65,0.01$, and $0.11 \mathrm{~g} \mathrm{~kg}^{-1}$, respectively. Monthly average temperature data for the two years and the 5-year average (2013-2017) during the growing season are presented in Figure 1. The average air temperature during the growing season was 23 and $22{ }^{\circ} \mathrm{C}$ in 2018 and 2019, respectively, while the 5-year average was $22^{\circ} \mathrm{C}$. Annual rainfall in 2018 and 2019 was 402 and $419 \mathrm{~mm}$, respectively, while the 5 -year average was $422 \mathrm{~mm}$. The monthly average PAR and total sunshine hour data for the two years during the cotton 
growing season are presented in Table 1 . The annual sunshine hours were 2165 and $2143 \mathrm{~h}$ in 2018 and 2019, respectively, while the 5-year average was $1927 \mathrm{~h}$. The average available PAR during the seedling and reproductive stages was higher than that during the other stages, while the average air temperature was lower. The whole cotton growing season was slightly cooler in 2019 than in 2018, and more rainfall occurred in 2019 than in 2018.

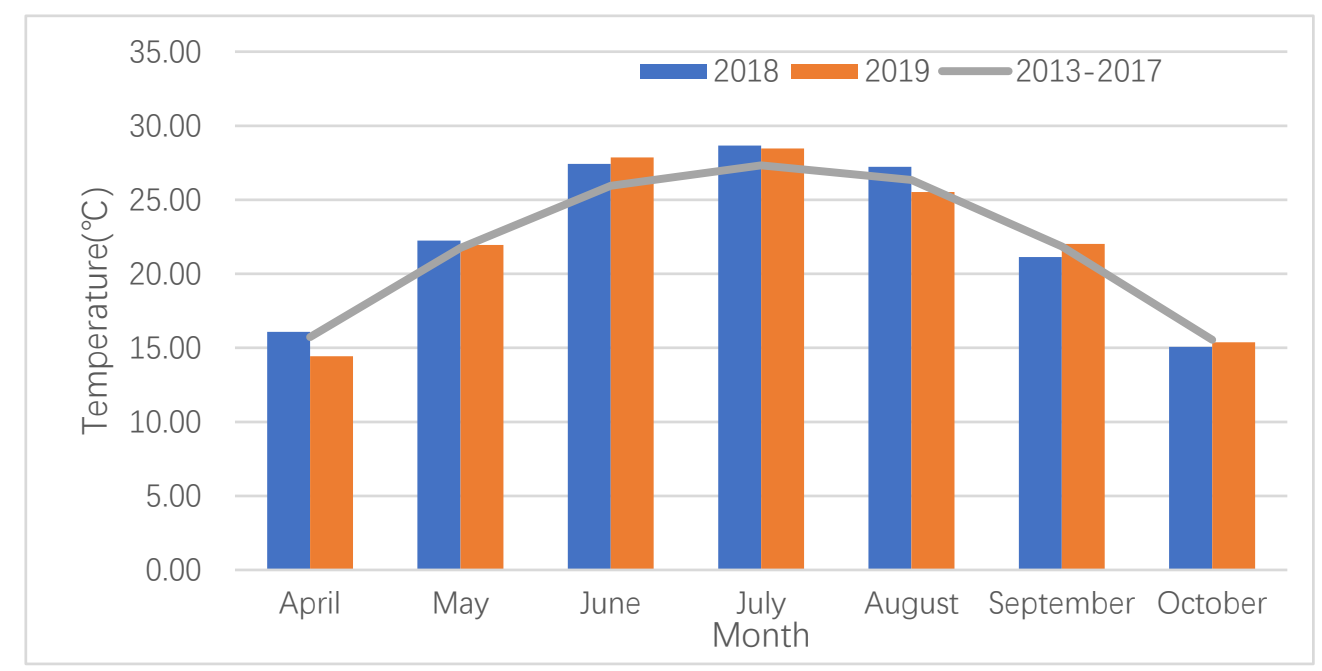

Figure 1. Temperature during the cotton growing season in 2018 and 2019 and the average for the preceding five years.

Table 1. Sunshine hours and daily photosynthetically active radiation (PAR) during the cotton growing season in 2018 and 2019.

\begin{tabular}{ccccccccc}
\hline Meteorological Data & Year & April & May & June & July & August & September & October \\
\hline Sunshine hours (h) & 2018 & 198.59 & 224.98 & 248.91 & 213.64 & 234.48 & 188.62 & 205.45 \\
& 2019 & 297.67 & 256.73 & 260.16 & 186.56 & 213.74 & 139.91 & 99.93 \\
\hline Daily PAR & 2018 & 348.58 & 398.81 & 469.74 & 418.51 & 388.82 & 310.04 & 234.28 \\
$\left(\mu \mathrm{mol} \cdot \mathrm{m}^{-2} \cdot \mathrm{s}^{-1}\right)$ & 2019 & 313.95 & 490.95 & 487.20 & 448.48 & 377.63 & 304.86 & 203.47 \\
\hline
\end{tabular}

\subsection{Experimental Design}

Three replicates each of six plant densities (D1: 1.5, D2: 3.3, D3: 5.1, D4: 6.9, D5: 8.7, D6: 10.5 plants $\mathrm{m}^{-2}$ ) of cotton variety SCRC28 were arranged in a randomized complete block design (RCBD). Each plot had an area of $64 \mathrm{~m}^{2}: 8 \mathrm{~m}$ in both length and width. Within each plot, the cotton was grown in 10 rows with row spacing of $0.8 \mathrm{~m}$. The growth periods of the cotton are shown in Table 2. Sowing was performed on 20 April 2018, and 18 April 2019. Before sowing, the field was irrigated with an approximate volume of water of $290 \mathrm{~m}^{3} \mathrm{ha}^{-1}$, and basal fertilizer was applied to the field $\left(225 \mathrm{~kg} \mathrm{ha}^{-1} \mathrm{~N}, 150 \mathrm{~kg} \mathrm{ha}^{-1}\right.$ $\mathrm{P}_{2} \mathrm{O}_{5}$, and $225 \mathrm{~kg} \mathrm{ha}^{-1} \mathrm{~K}_{2} \mathrm{O}$ ). Medium-term management involved mechanical cultivation methods for weeding and spraying pesticides and plant growth regulators, and chemical control methods were used to control pests and diseases.

\subsection{Data Collection}

Data on light interception, leaf area, biomass accumulation and plant height and yield were collected and recorded at specific stages of cotton growth during 2018 and 2019 on different days after emergence (DAE). 
Table 2. Cotton growth stages according to the different plant densities in 2018 and 2019.

\begin{tabular}{|c|c|c|c|c|c|}
\hline Treatment & Emergence/DAE ${ }^{1}$ & Seedling/DAE & Squaring/DAE & Flowering/DAE & $\begin{array}{c}\text { Boll } \\
\text { Opening/DAE }\end{array}$ \\
\hline \multicolumn{6}{|c|}{ Year 2018} \\
\hline D1 & April 28/0 & May $17 / 19$ & May 29/31 & June $24 / 57$ & August $6 / 100$ \\
\hline D2 & April 28/0 & May $17 / 19$ & May $30 / 32$ & June $25 / 58$ & August 8/102 \\
\hline D3 & April 28/0 & May $17 / 19$ & May $30 / 32$ & June $25 / 58$ & August 8/102 \\
\hline D4 & April 28/0 & May $17 / 19$ & May $30 / 32$ & June $25 / 58$ & August $10 / 104$ \\
\hline D5 & April 28/0 & May $17 / 19$ & May $30 / 32$ & June $25 / 58$ & August $10 / 104$ \\
\hline D6 & April 28/0 & May $17 / 19$ & May $31 / 33$ & June $27 / 60$ & August $13 / 107$ \\
\hline \multicolumn{6}{|c|}{ Year 2019} \\
\hline D1 & April 28/0 & May 20/22 & May 28/30 & June $24 / 57$ & August $14 / 108$ \\
\hline D2 & April 28/0 & May $20 / 22$ & May $28 / 30$ & June $24 / 57$ & August 15/109 \\
\hline D3 & April 28/0 & May $20 / 22$ & May 30/32 & June $24 / 57$ & August 15/109 \\
\hline D4 & April 28/0 & May $20 / 22$ & May 30/32 & June $24 / 57$ & August $16 / 110$ \\
\hline D5 & April 28/0 & May $20 / 22$ & May $31 / 33$ & June 26/59 & August 17/111 \\
\hline D6 & April 28/0 & May $20 / 22$ & May 31/33 & June 26/59 & August 19/112 \\
\hline
\end{tabular}

${ }^{1}$ DAE: Day after emergence.

\subsubsection{Light Interception}

Light interception data were collected during the growing season at an interval of 15 days at 30, 45, 60, 75, 90, 105 and 120 DAE. Data were collected on a sunny day with no clouds, and the measurements began at $10 \mathrm{a} . \mathrm{m}$. and finished half an hour later. Two specific rows of cotton were selected to measure light interception in each plot. In this study, the spatial grid method was used to identify stable measurement points in two cotton rows. In terms of horizontal distance, $0,20,40,60$ and $80 \mathrm{~cm}$ were selected as the measurement points. For vertical distance, the distance from the ground to the top of the canopy was divided into layers considering an interval of $20 \mathrm{~cm}$. In this way, a spatial grid perpendicular to the cotton plants was obtained, and the measurement points in the two cotton rows are shown in Figure 2.

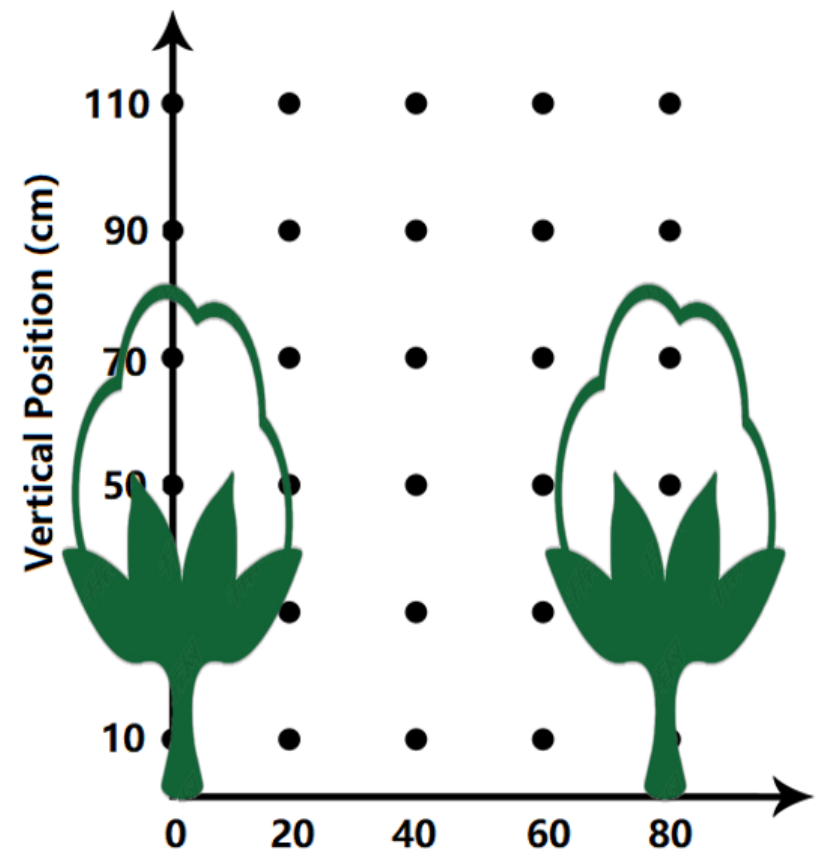

Horizional Position (cm)

Figure 2. The measurement points in the two cotton rows of cotton plot. 
For each measurement point, a $1 \mathrm{~m}$-long portable linear light quantum sensor (LI191SA, LI-COR, Lincoln, NE, USA) was used to measure the intercepted PAR intensity and the reflected PAR intensity, and a LI-1400 instrument (LI-COR, Lincoln, NE, USA) was used to collect and record the data. When the measurements were performed at the various points, the sensor was placed parallel to the row direction and faceup to measure the intercepted PAR intensity and then reversed and placed facedown to measure the reflected PAR intensity. At the same time, another sensor was placed $20 \mathrm{~cm}$ above the cotton canopy to record the total intensity of the real-time PAR. Each sensor automatically recorded the total intensity of real-time incident PAR every $5 \mathrm{~s}$.

A coordinate system was created in the vertical direction for the testing area, and the locations of the points measured and to be measured in a particular section of the testing area were used to create a $\operatorname{Grid}_{(\mathrm{i}, \mathrm{j})}$ file. Each element of the file recorded the position of the point measured and to be measured in the vertical direction. $i$ and $j$ represented the abscissas and ordinates of the section of the testing area, respectively. To evaluate the differences in light interception among the different densities of cotton, the grid math operation in Surfer software (Golden Software Inc., Golden, CO, USA) was used:

$$
\text { Grid } C_{(i, j)}=\operatorname{Grid~} A_{(i, j)}-\operatorname{Grid~} B_{(i, j)}
$$

The fraction of intercepted PAR (iPAR), PAR reflectance (rPAR) and PAR transmittance (tPAR) at each measurement point in the cotton canopy were calculated according to Tang's method [29]. tPAR was determined by dividing transmitted PAR intensity by total incident PAR intensity, and rPAR was calculated by dividing reflected PAR intensity by total incident PAR intensity.

According to a study by Zhi [23], under a planting density of 60,000 plants/ha, light reflectance of the cotton plants is only $3-5 \%$, which has little effect on the growth and development of cotton. Therefore, in the current study, the influence of reflected light on the growth and development of cotton was ignored. Therefore, the iPAR was calculated according to the formula below:

$$
\mathrm{iPAR}=1-\mathrm{tPAR}-\mathrm{rPAR}
$$

The cumulative interception rate and transmittance in the canopy of the entire population can be calculated in Surfer software with the extension of Simpson's 3/8 rule. The formula is as follows:

$$
\begin{gathered}
A_{i}=\frac{3 \Delta X}{8}\left(G_{i, 1}+3 G_{i, 2}+3 G_{i, 3}+2 G_{i, 4}+\cdots+2 G_{i, n c o l-1}+G_{i, n c o l}\right) \\
V \approx \frac{3 \Delta y}{8}\left(A_{1}+3 A_{2}+3 A_{3}+2 A_{4}+\cdots+2 A_{n c o l-1}+A_{n c o l}\right)
\end{gathered}
$$

where $G_{i j}$ is the $i$ th row and $j$ th column of the grid point excavation depth; $A_{i}$ is the $i$ th cross-sectional area; and $\Delta X$ and $\Delta y$ are the grid data file column and row distances, respectively. The coefficients for Equations (3) and (4) are $[1,3,3,2, \ldots \ldots$, . 3,3,2,1].

\subsubsection{Leaf Area}

The LAI of the cotton plants was measured by collecting all leaves from two randomly selected plants growing in each plot and using a flatbed scanner (Phantom p800xl, MiCROTEK, Shanghai, China) to take photos of the leaves. The leaf images were processed with Image-Pro Plus 7.0 software. (Media Cybernetics, Rockville, MD, USA). Then, the total leaf area of a single plant was calculated. The LAI was determined by dividing total leaf area per plant by corresponding ground area.

\subsubsection{Plant Height}

Two plants were randomly selected and uprooted from the middle rows in each plot, and their height was measured using a ruler. The length from the cotyledon to the growth 
point of the plant was considered the height of a single plant. Average plant height was calculated with the data from all the selected plants from each treatment.

\subsubsection{Biomass}

The dry weight of the cotton plants was determined by collecting samples at an interval of approximately 15 days during the growing season at 30,45, 60, 79, 87, 102 and 117 DAE in 2018 and at 30, 45, 60, 74, 88, 99, 116 and 129 DAE in 2019. Two plants from each plot were uprooted and separated into underground parts (roots), leaves, stems and reproductive parts. The samples were placed into an electric fan-assisted oven at $105^{\circ} \mathrm{C}$ for $30 \mathrm{~min}$ to stop metabolism. The samples were then dried at $80{ }^{\circ} \mathrm{C}$ for $48 \mathrm{~h}$ until a constant weight was achieved. A logistic regression formula was used to calculate biomass accumulation [30]:

$$
Y=\frac{\mathrm{A}}{1+\mathrm{b} e^{-k t}}
$$

In Formula (5), where $Y(\mathrm{~kg})$ represents biomass, $\mathrm{A}(\mathrm{kg})$ represents the maximum biomass, $t(\mathrm{~d})$ is the DAE, and $\mathrm{b}$ and $k$ are constants.

The following formulas were calculated from Formula (5):

$$
\begin{gathered}
t_{0}=\frac{\operatorname{lnb}}{\mathrm{k}}\left(t_{0}=t\right) \\
t_{1}=\frac{\ln b-\ln (2-\sqrt{3})}{\mathrm{k}} \\
t_{2}=\frac{\ln b-\ln (2+\sqrt{3})}{\mathrm{k}} \\
V_{M}=\frac{\mathrm{Ak}}{4} \\
V_{A}=\frac{Y_{2}-Y_{1}}{\Delta_{t}}
\end{gathered}
$$

In the formulas above, $V_{M}$ represents the highest rate of biomass accumulation, $t$ represents the fast accumulation period of maximum biomass, $Y_{1}$ and $Y_{2}$ represent the current biomass at $t_{1}$ and $t_{2}, V_{A}$ is the average biomass accumulation from $t_{1}$ to $t_{2}$, and $\Delta t$ is the total period of biomass accumulation.

\subsubsection{Yield}

Seed cotton yield and lint yield were measured after harvest, and the plants in each treatment were harvested three times each year. Lint percentage was calculated by dividing lint yield by seed cotton yield of 100 bolls.

\subsubsection{Statistical Analysis}

Microsoft Excel 2019 (Microsoft, Bothell, WA, USA) and Stata 16.0 (Stata Corporation, College Station, TX, USA) were used to process the data. SPSS 19.0 (SPSS Inc., Chicago, IL, USA) and Origin 2016 (OriginLab Corporation, Northampton, MA, USA) were used to analyze the yield and biomass data. Image-Pro Plus 6.0 was used to calculate the LAI. Light interception data were processed and analyzed in Stata 16.0, Surfer 18 (Golden Software Inc., Golden, CO, USA) and GS + 9.0 (Gamma Design Software Inc, Plainwell, MI, USA). Duncan's multiple range test at the 5\% probability level was used to test the differences among the mean values. 


\section{Results}

\subsection{Light Interception}

\subsubsection{Light Interception at Different Points}

The light interception data were collected and analyzed the different positions of iPAR and the variation in light interception during the flowering stage to assess the competition for light among the different densities of cotton plants. According to Figure 3, light interception varied at different canopy positions. In 2018, the trend of iPAR ranged from 0.45 to 0.80 (low densities), 0.50 to 0.83 (medium densities), and 0.50 to 0.92 (high densities) at $50 \mathrm{~cm}$ in the vertical direction. iPAR decreased from bottom to the top of the cotton canopy, and there was no significant difference at the top of cotton canopies among different plant densities.
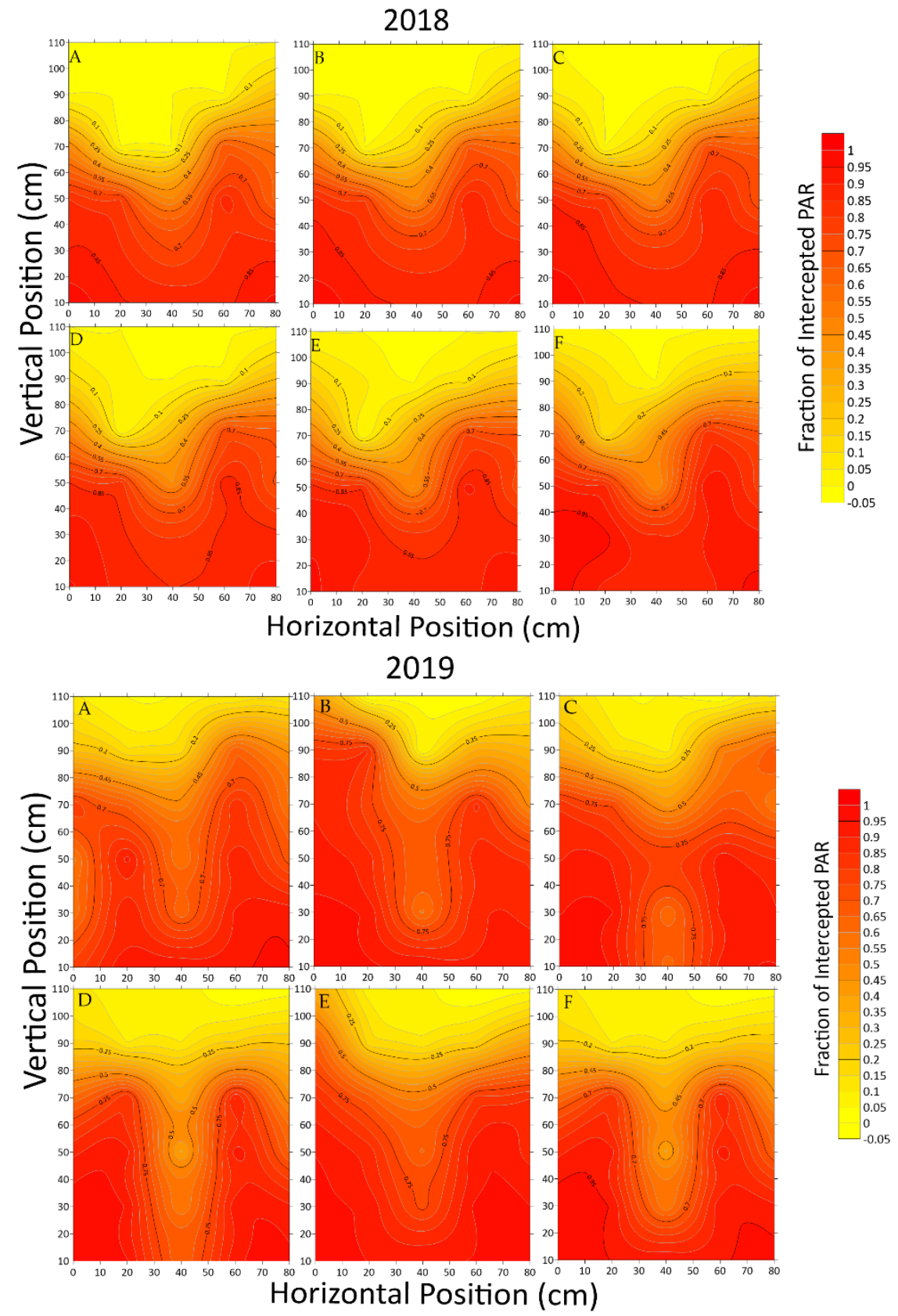

Figure 3. Light interception during the flowering stage at different cotton plant densities in 2018 and 2019. (A) D1; (B) D2; (C) D3; (D) D4; (E) D5; (F) D6. 
At each layer of the cotton canopies, light interception near the cotton rows was significantly higher than at the inter-row of cotton, with a value of $0.6-0.85$ near the cotton rows and $0.45-0.75$ at the inter-row of cotton. In addition, there was significant difference of light interception near cotton rows. However, there was no significant difference of light interception at the inter-row of cotton canopies, as the iPAR ranged from 0 to 0.85 in all plant densities at $50 \mathrm{~cm}$ in the horizontal direction. Additionally, light interception increased with increasing plant populations, with the trend of iPAR ranges from 0 to 0.85 (low densities), 0 to 0.90 (medium densities), and 0 to 0.95 (high densities). The result of 2019 showed the same trend of 2018, with the iPAR ranging from 0.42 to 0.85 (low densities), 0.50 to 0.97 (medium densities), and 0.44 to 0.98 (high densities) near the cotton rows at $30-80 \mathrm{~cm}$ in the vertical direction.

\subsubsection{Variation of Light Interception in Different Positions}

iPAR varied at different cotton plant densities, with the highest iPAR observed at high densities. Figures 4 and 5 shows the variation in light interception by the whole cotton canopy associated with different plant densities for the two years, and each figure shows the iPAR differences between adjacent densities. According to the contour plots for the two years, the high densities of cotton plants showed a higher fraction of light interception than the low populations when adjacent densities were considered, with the value of iPAR variation ranging from -0.005 to 0.150 . On the basis of vertical distance, most variation in the iPAR ranged from 0 to 0.02 during the two evaluated years, except for D5-D4 and D6-D5 in 2019, for which the range was 0-0.045. At the level of 40-80 cm, iPAR variation was 0-0.14 for D2-D1, 0-0.055 for D3-D2, D4-D3 and D5-D4 and 0-0.125 for D6-D5. At a height below $40 \mathrm{~cm}$, iPAR variations were $0-0.05$ for all comparisons. In addition, the results show that there were no significant differences at a height above $80 \mathrm{~cm}$, while at a height below $80 \mathrm{~cm}$, high-densities cotton plants showed a higher fraction light interception than the plants growing at a lower density. In terms of the horizontal position, most of iPAR variation values at a position between 30 and $50 \mathrm{~cm}$ ranged from -0.005 to 0.05 in 2018 and from -0.05 to 0.02 in 2019 , showing that the variation in light interception by cotton plants did not obviously differ at the midpoint of the rows. However, most of the variation in iPAR at positions below $30 \mathrm{~cm}$ and above $80 \mathrm{~cm}$ ranged from -0.005 to 0.15 during the two evaluated years, indicating that there was little difference in light interception among the different plant densities, as the high densities of cotton plants were associated with high light interception.

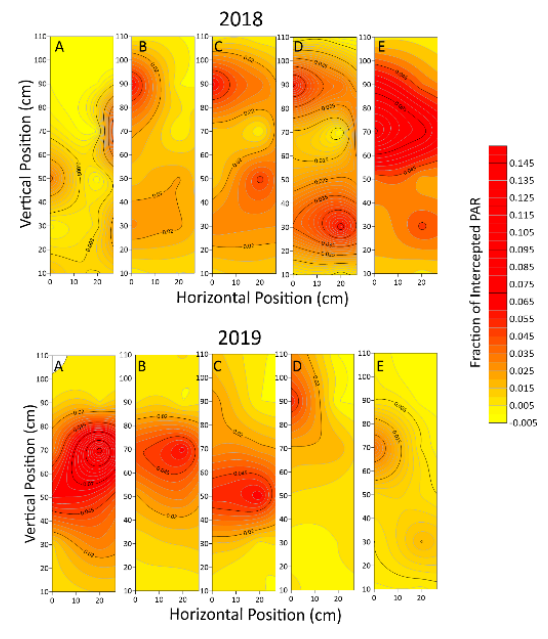

(a)

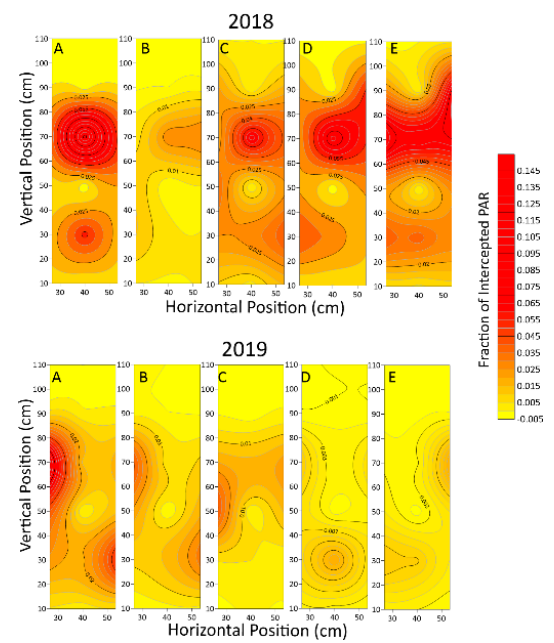

(b)

Figure 4. Variation in light interception at different positions in the canopy of plants growing at different densities in 2018 and 2019. (a) Near the cotton rows; (b) midpoint; (A) D2-D1; (B) D3-D2; (C) D4-D3; (D) D5-D4; (E) D6-D5. 


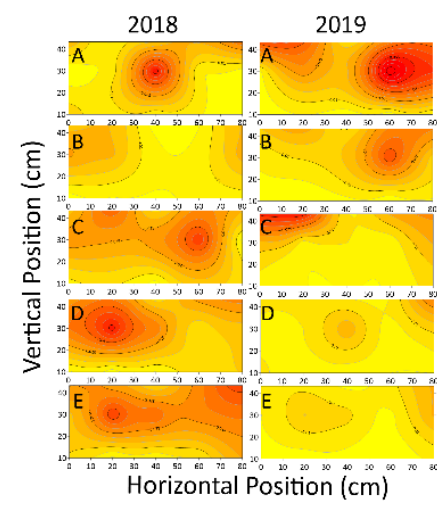

(a)

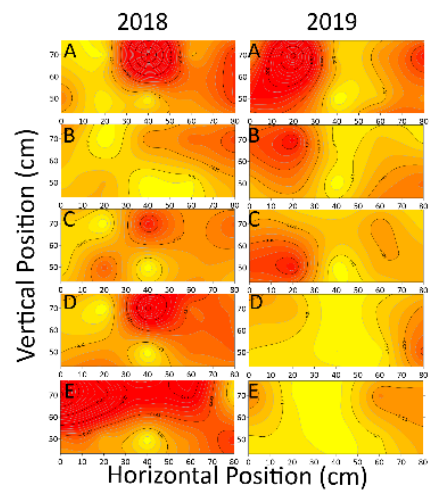

(b)

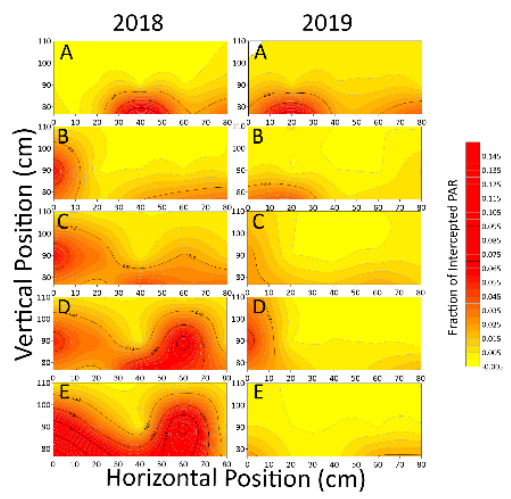

(c)

Figure 5. Variation in light interception at different levels in the canopy of plants growing at different densities in 2018 and 2019. (a) Bottom of the canopy; (b) middle of the canopy; (c) top of the canopy; (A) D2-D1; (B) D3-D2; (C) D4-D3; (D) D5-D4; (E) D6-D5.

\subsection{Leaf Area}

The total leaf area of a single plant and the LAI changed linearly on different DAE during the cotton-growing period. Total leaf area values of a single plant at different planting densities are shown in Figure 6.
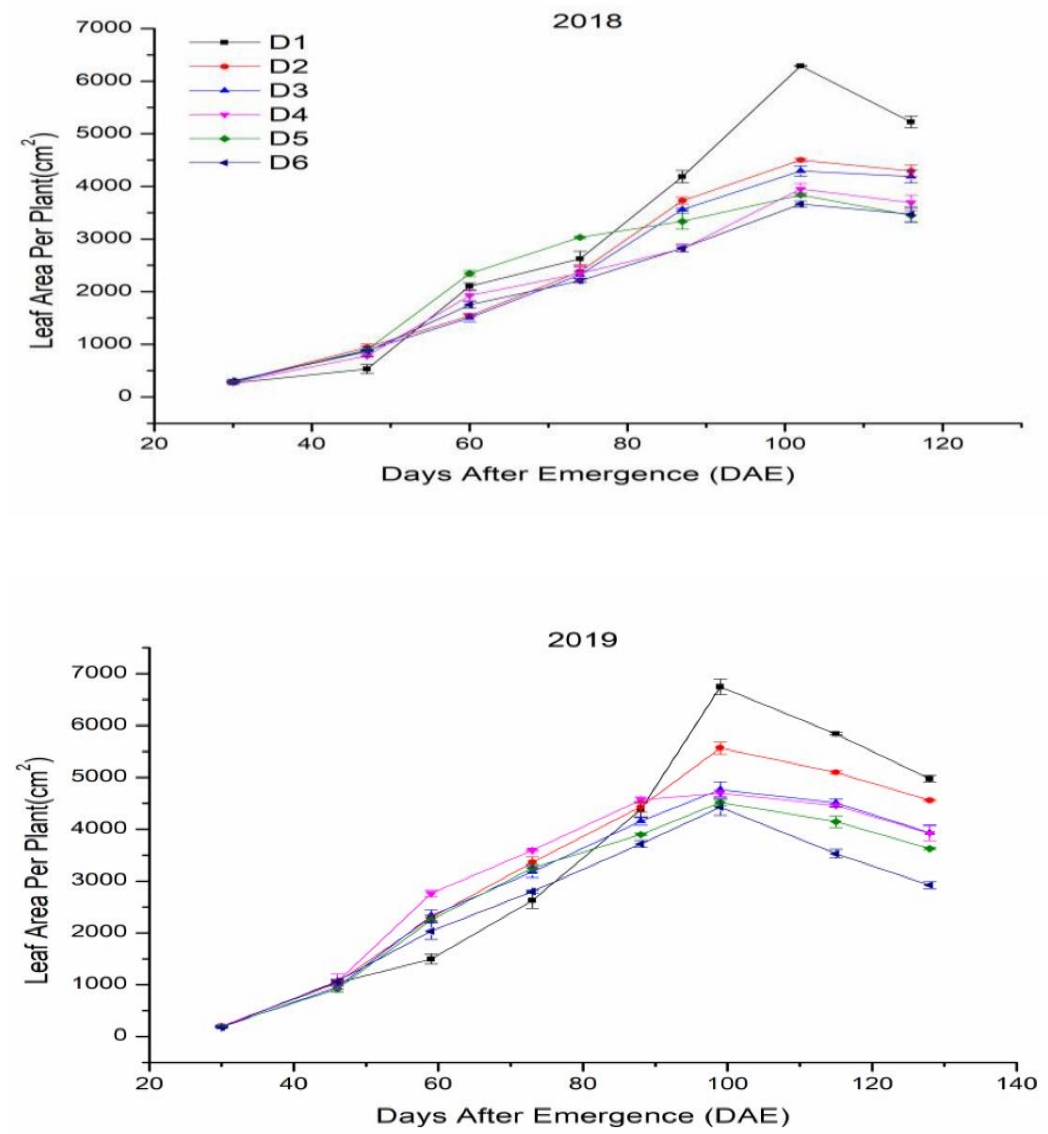

Figure 6. Leaf area per cotton plant growing at different planting densities in 2018 and 2019.

Total leaf area of a single plant first increased, reached a peak at approximately $100 \mathrm{DAE}$, and then decreased over the course of the growth period in both years. Before $80 \mathrm{DAE}$ in both years there was no significant difference between different plant densities 
in terms of leaf area. However, after $80 \mathrm{DAE}$, leaf area at D1 was higher than that at any other density during both years, and leaf area decreased as plant density increased.

The plants growing at the highest density reached a maximum leaf area of $4292.93 \mathrm{~cm}^{2}$ in 2018 and $4515.84 \mathrm{~cm}^{2}$ in 2019, while those growing at the lowest density reached a maximum leaf area of $6288.16 \mathrm{~cm}^{2}$ in 2018 and $6745.95 \mathrm{~cm}^{2}$ in 2019 .

The LAI at D6 was higher than that at any other density during both years over the course of the whole growing period, and the LAI increased as plant density increased. The LAI first increased with the growth of the plants in both years, reached a peak at approximately 102 DAE and then decreased (Figure 7).
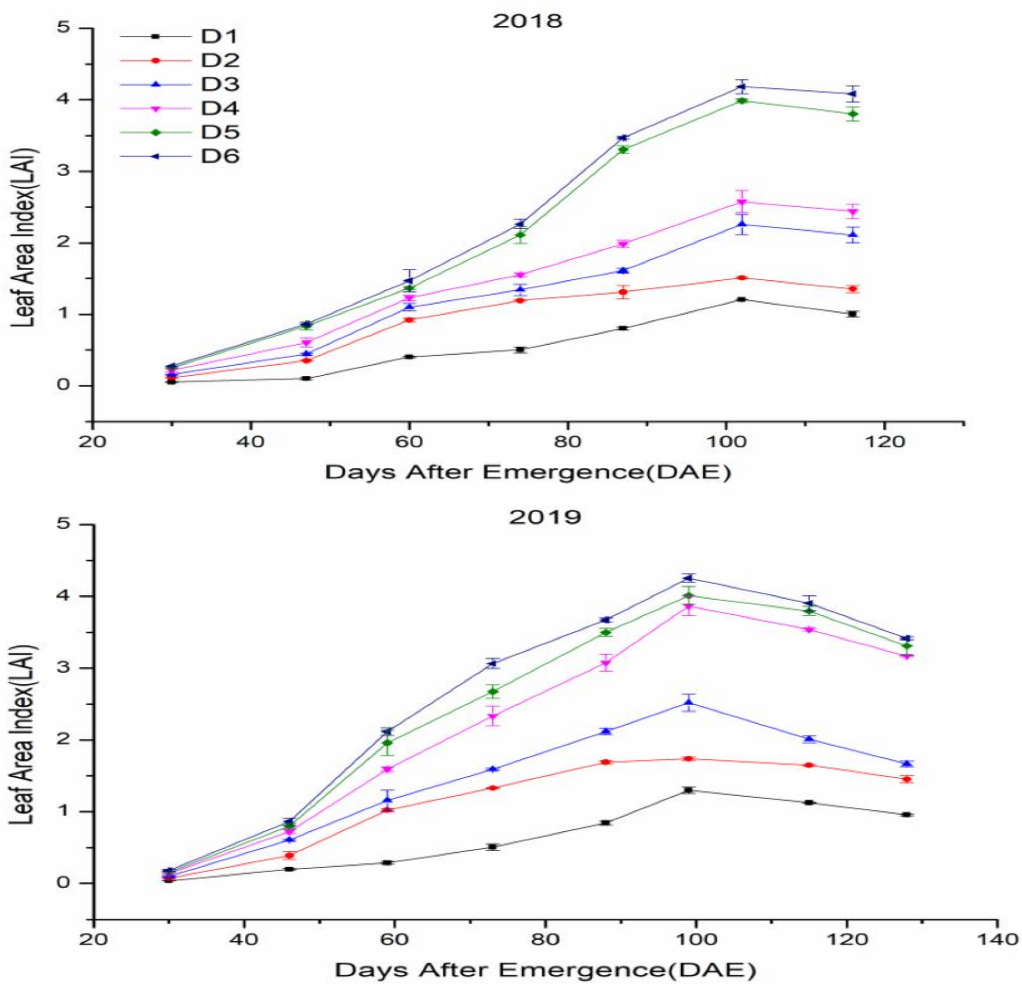

Figure 7. Leaf area index of cotton plants growing at different planting densities in 2018 and 2019.

The plants growing at the highest density reached a maximum LAI of 4.18 in 2018 and 4.25 in 2019, while those growing at the lowest density reached a maximum LAI of 1.20 in 2018 and 1.31 in 2019.

\subsection{Plant Height}

Cotton plant height increased during the whole growing period, with plant heights in the order of D6 $>\mathrm{D} 5>\mathrm{D} 4>\mathrm{D} 3>\mathrm{D} 2>\mathrm{D} 1$ during both years during the whole growing period. The results for the two years showed the same trends in plant height (Figure 8).

The plants growing at the highest density reached a maximum plant height of $95.33 \mathrm{~cm}$ at 87 DAE in 2018 and $121.83 \mathrm{~cm}$ at 107 DAE in 2019, while those growing at the lowest density reached a maximum height of $77.83 \mathrm{~cm}$ at 87 DAE in 2018 and $100.33 \mathrm{~cm}$ at 107 DAE in 2019.

\subsection{Biomass}

\subsubsection{Aboveground Biomass of Individual Plants}

Cotton plant aboveground biomass associated with each density followed a normal logistic model, and that at the lowest density (D1) was higher than that at any other density during both years over the whole growing period (Figure 9). 

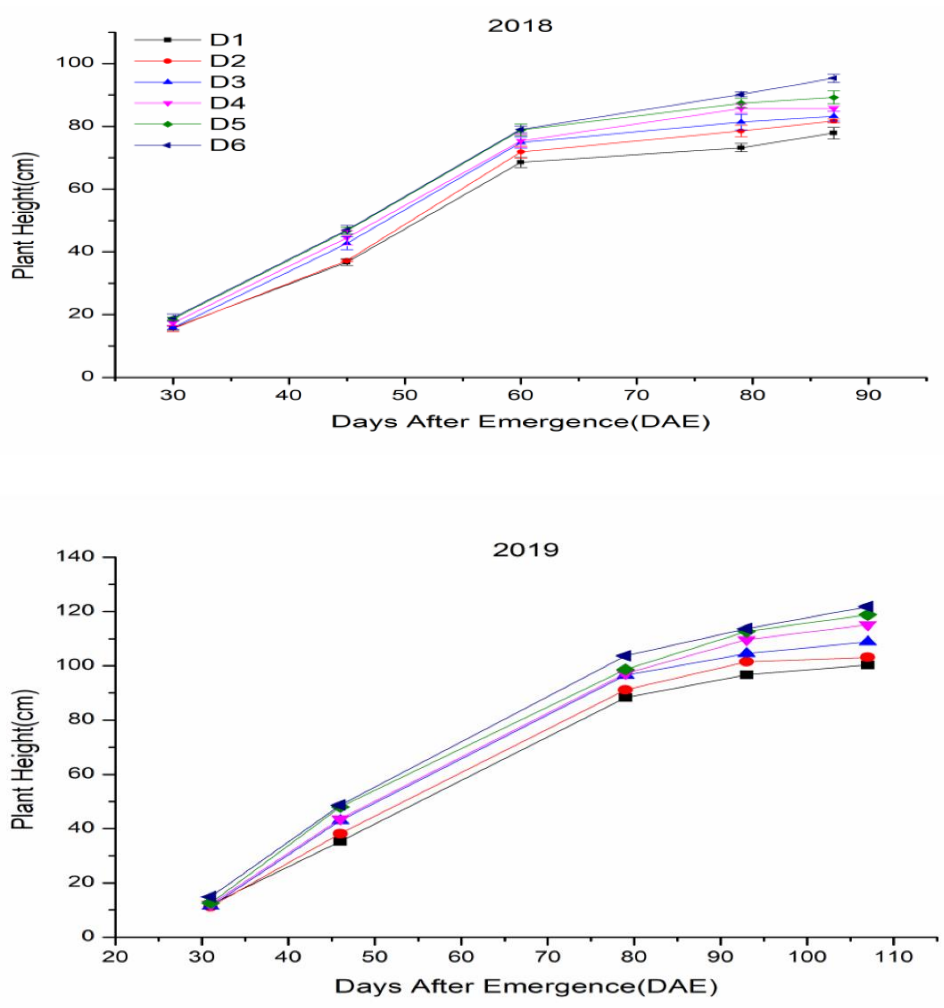

Figure 8. Cotton plant height at different planting densities in 2018 and 2019.
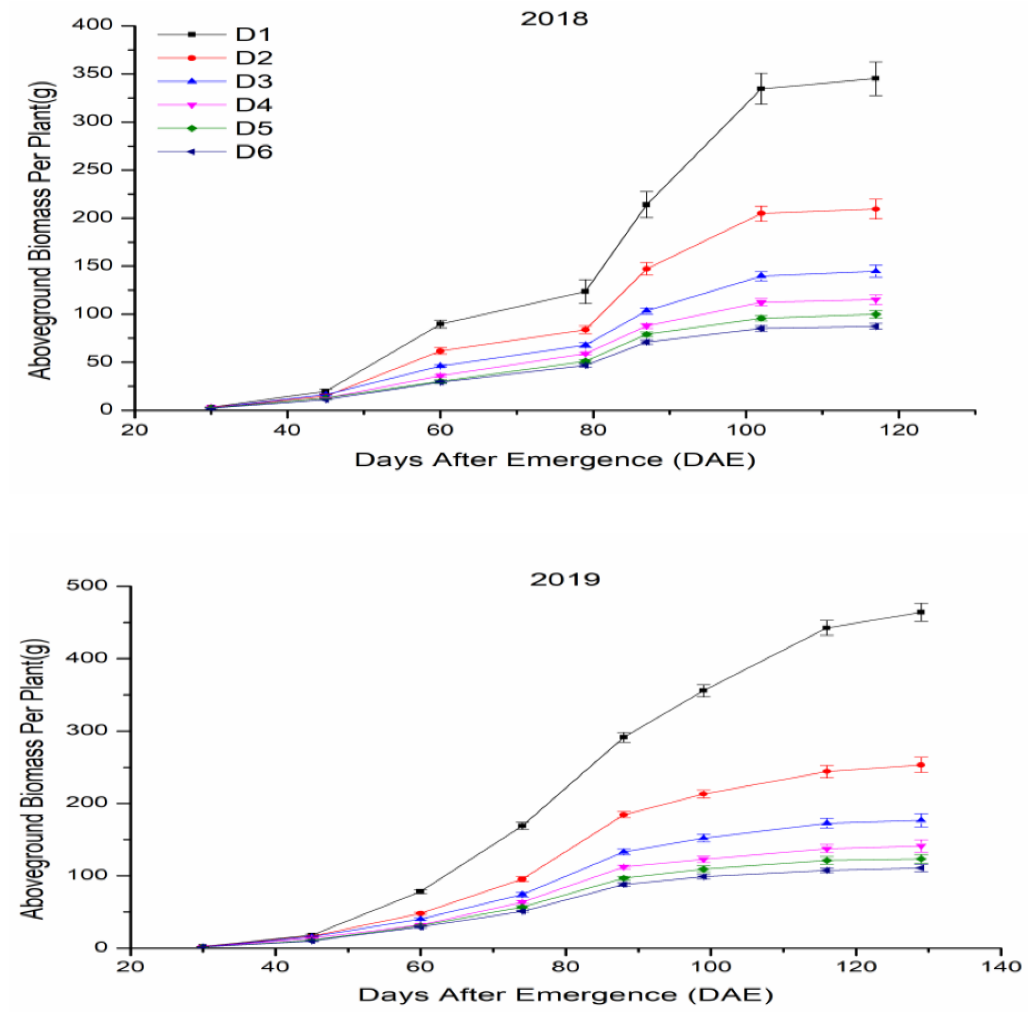

Figure 9. The aboveground biomass of a single cotton plant grown at different planting densities in 2018 and 2019.

The plants growing at the lowest density reached a maximum aboveground biomass of $345.06 \mathrm{~g}$ at $117 \mathrm{DAE}$ in 2018 and $464.21 \mathrm{~g}$ at $129 \mathrm{DAE}$ in 2019, while those growing at 
the highest density reached an aboveground biomass of $87.35 \mathrm{~g}$ at 117 DAE in 2018 and $110.85 \mathrm{~g}$ at $129 \mathrm{DAE}$ in 2019.

\subsubsection{Aboveground Biomass Accumulation}

The cotton aboveground biomass significantly followed a normal logistic model on the basis of DAE (Tables 3 and 4), and the aboveground biomass of the D6 population was higher than that at any other density during both years over the whole growing period (Figure 10). The simulation of biomass accumulation was based on Formula (5). Table 3 illustrates the starting and ending days of the fast accumulation period during 2018 and 2019 , and the maximum aboveground biomass of all plants $\left(1149.106 \mathrm{gm} \mathrm{m}^{-2} \mathrm{~d}^{-1}\right)$ can be calculated. The average highest speeds of aboveground biomass accumulation for all plants were 55 and 102 DAE in 2018 and 61 and 93 DAE in 2019, with the highest average $\left(V_{A}=11.5\right.$ and $\left.17.0 \mathrm{gm} \mathrm{m}^{-2} \mathrm{~d}^{-1}\right)$ and maximum rates $\left(V_{M}=13.1\right.$ and $\left.19.4 \mathrm{gm} \mathrm{m}^{-2} \mathrm{~d}^{-1}\right)$ (Table 3).

Table 3. Eigen values of cotton biomass accumulation in the 2018 and 2019 growing season.

\begin{tabular}{|c|c|c|c|c|c|c|c|}
\hline \multirow{2}{*}{ Treatment } & \multirow{2}{*}{$A\left(\mathrm{gm} \mathrm{m}^{-2} \mathrm{~d}^{-1}\right)$} & \multicolumn{4}{|c|}{ Fast Accumulation Period } & \multicolumn{2}{|c|}{ Fastest Accumulation Point } \\
\hline & & $t_{1}$ (DAE) & $t_{2}$ (DAE) & $\Delta t(\mathrm{~d})$ & $V_{A}\left(\mathrm{gm} \mathrm{m}^{-2} \mathrm{~d}^{-1}\right)$ & $V_{M}\left(\mathrm{gm} \mathrm{m}^{-2} \mathrm{~d}^{-1}\right)$ & at DAE \\
\hline \multicolumn{8}{|c|}{ Year 2018} \\
\hline D1 & 609.105 & 64.0 & 108.0 & 44.1 & 8.0 & 9.1 & 86.0 \\
\hline D2 & 784.542 & 58.4 & 100.3 & 41.9 & 10.8 & 12.3 & 79.4 \\
\hline D3 & 936.003 & 54.9 & 104.6 & 49.6 & 10.9 & 12.4 & 79.7 \\
\hline D4 & 1025.805 & 54.5 & 101.7 & 47.2 & 12.6 & 14.3 & 78.1 \\
\hline D5 & 1130.505 & 51.3 & 100.3 & 49.0 & 13.3 & 15.2 & 75.8 \\
\hline D6 & 1149.106 & 48.9 & 99.4 & 50.5 & 13.1 & 15.0 & 74.2 \\
\hline Average & & 55.3 & 102.4 & 47.0 & 11.5 & 13.1 & 78.9 \\
\hline \multicolumn{8}{|c|}{ Year 2019} \\
\hline D1 & 716.274 & 64.7 & 100.5 & 35.8 & 11.1 & 13.2 & 82.6 \\
\hline D2 & 843.626 & 63.0 & 94.1 & 31.1 & 15.6 & 17.8 & 78.6 \\
\hline D3 & 918.050 & 60.2 & 93.2 & 33.0 & 16.0 & 18.3 & 76.7 \\
\hline D4 & 982.470 & 59.3 & 90.7 & 31.4 & 18.8 & 20.6 & 75.0 \\
\hline D5 & 1091.457 & 58.6 & 91.0 & 32.4 & 19.3 & 22.2 & 74.8 \\
\hline D6 & 1177.606 & 58.2 & 90.4 & 32.2 & 21.0 & 24.1 & 74.3 \\
\hline Average & & 60.7 & 93.3 & 32.6 & 17.0 & 19.4 & 77.0 \\
\hline
\end{tabular}

$t_{1}$ is the starting point and $t_{2}$ is the ending point of the fast accumulation period (FAP). $D_{t}$ is the total duration of the FAP. $V_{A}$ is the average and $V_{M}$ is the maximum rate of biomass accumulation during the FAP. DAE represents days after emergence.

Table 4. Simulation of plant biomass accumulation according to plant density during the cotton growing seasons of 2018 and 2019.

\begin{tabular}{ccc}
\hline Treatment & Regression Equation & $\mathbf{R}^{\mathbf{2}}$ \\
\hline Year 2018 & $\mathrm{Y}=6091.05095 /\left(1+170.72 \mathrm{e}^{-0.05978 \mathrm{t}}\right)$ & $0.985^{* * *}$ \\
D1 & $\mathrm{Y}=7845.41809 /\left(1+147.37 \mathrm{e}^{-0.0629 \mathrm{t}}\right)$ & $0.993^{* * *}$ \\
D2 & $\mathrm{Y}=9360.03681 /\left(1+68.70 \mathrm{e}^{-0.05305 \mathrm{t}}\right)$ & $0.992^{* * *}$ \\
D3 & $\mathrm{Y}=10,258.05161 /\left(1+78.27 \mathrm{e}^{-0.05585 \mathrm{t}}\right)$ & $0.991^{* * *}$ \\
D4 & $\mathrm{Y}=11,305.05257 /\left(1+59.01 \mathrm{e}^{-0.05377 \mathrm{t}}\right)$ & $0.989^{* * *}$ \\
D5 & $\mathrm{Y}=11,491.06419 /\left(1+47.72 \mathrm{e}^{-0.05211 \mathrm{t}}\right)$ & $0.989^{* * *}$ \\
D6 & & \\
Year 2019 & $\mathrm{Y}=7162.73984 /\left(1+433.56 \mathrm{e}^{-0.07351 \mathrm{t}}\right)$ & $0.998^{* * *}$ \\
D1 & $\mathrm{Y}=8436.2559 /\left(1+772.58 \mathrm{e}^{-0.08463 \mathrm{t}}\right)$ & $0.997^{* * *}$ \\
D2 & $\mathrm{Y}=9180.49668 /\left(1+455.31 \mathrm{e}^{-0.07978 \mathrm{t}}\right)$ & $0.997^{* * *}$ \\
D3 & $\mathrm{Y}=9824.69778 /\left(1+544.36 \mathrm{e}^{-0.08399 \mathrm{t}}\right)$ & $0.996^{* * *}$ \\
D4 & $\mathrm{Y}=10,914.569 /\left(1+439.83 \mathrm{e}^{-0.0814 \mathrm{t}}\right)$ & $0.997^{* * *}$ \\
D5 & $\mathrm{Y}=11,776.0588 /\left(1+436.68 \mathrm{e}^{-0.08186 \mathrm{t}}\right)$ & $0.996^{* * *}$ \\
D6 & & \\
\hline
\end{tabular}

*** Significant at the 0.001 probability level. 

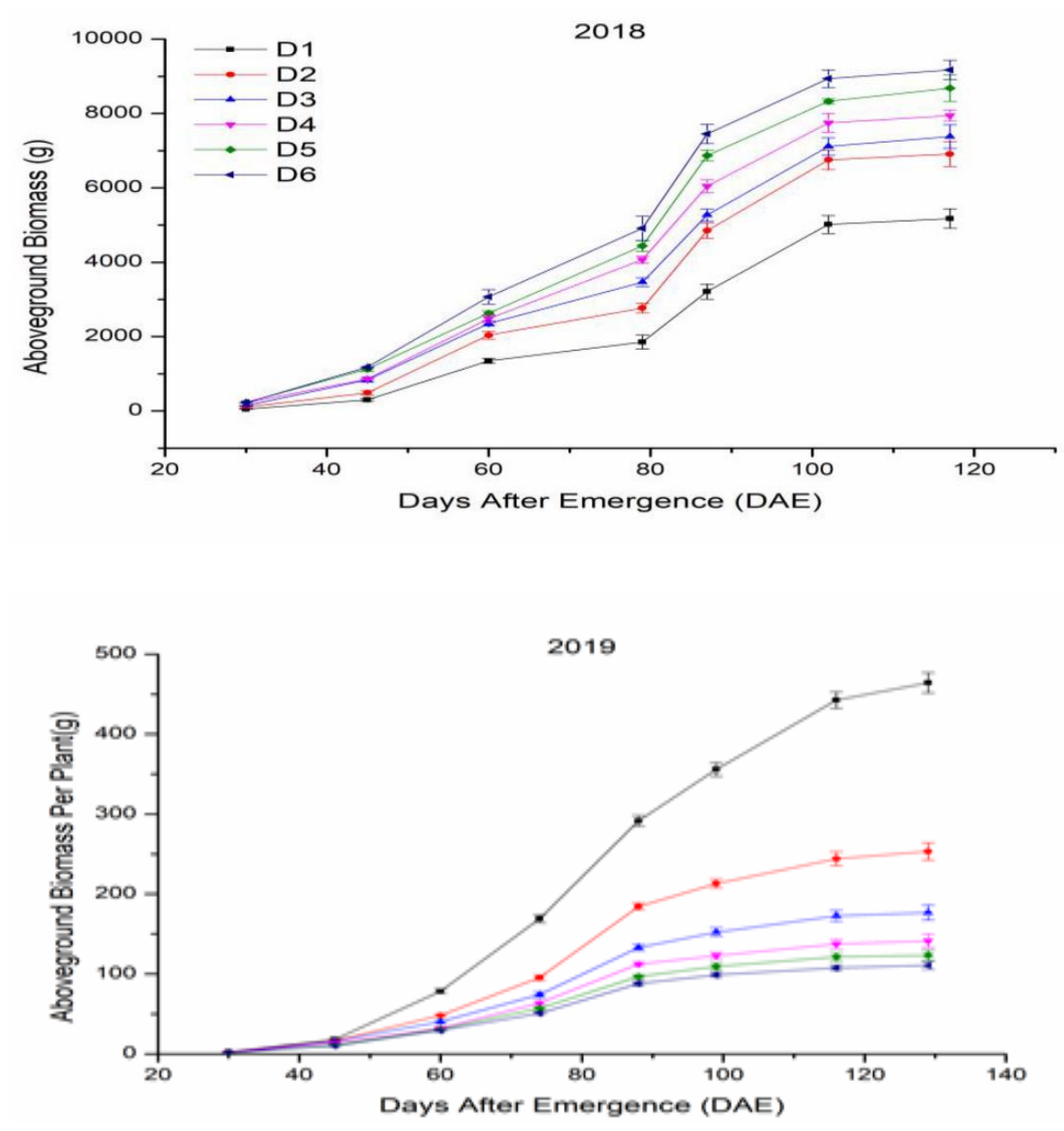

Figure 10. The aboveground biomass of cotton grown at different planting densities in 2018 and 2019.

\subsection{The Relationships and Fitted Models}

In this study, light interception data of each plot were calculated to observe the relationships with leaf area, aboveground biomass and plant height. As shown in Figures 11-15, across the different densities of cotton, the aboveground biomass of single plant was linearly related to cumulative iPAR in both years, with $\mathrm{R}^{2}$ values of 0.95 and 0.91 , respectively, there was also a linear relationship between iPAR and plant height in this study, with $\mathrm{R}^{2}$ values of 0.93 and 0.91 , respectively. The leaf area of single plant had a highly significant logarithmic correlation with iPAR, with $\mathrm{R}^{2}$ values of 0.89 and 0.87 , respectively. For cotton populations, the LAI had a highly significant logarithmic correlation with iPAR, with $\mathrm{R}^{2}$ values of 0.83 and 0.74 , respectively. The aboveground biomass were linearly related to cumulative iPAR, with $\mathrm{R}^{2}$ values of 0.93 and 0.92 .
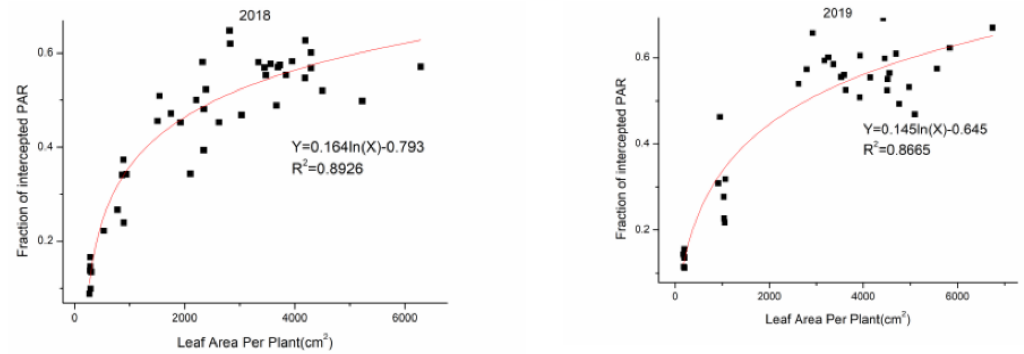

Figure 11. Relationships and fitted models of intercepted PAR (iPAR) and leaf area per plant in 2018 and 2019. 

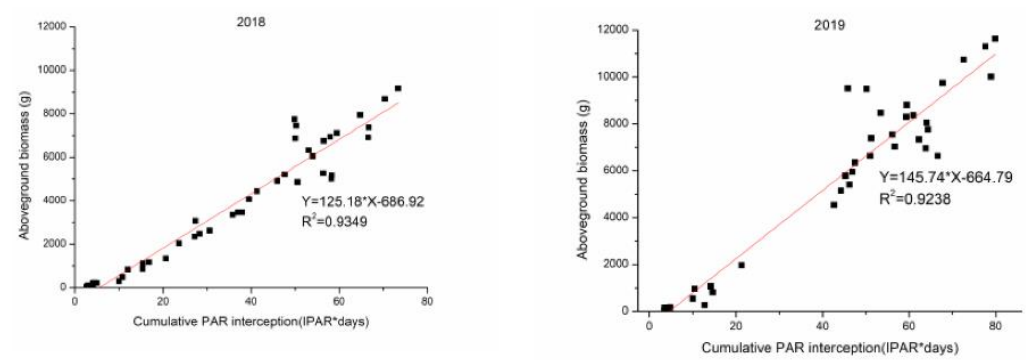

Figure 12. Relationships and fitted models for the cumulative PAR interception and aboveground biomass per plant in 2018 and 2019.
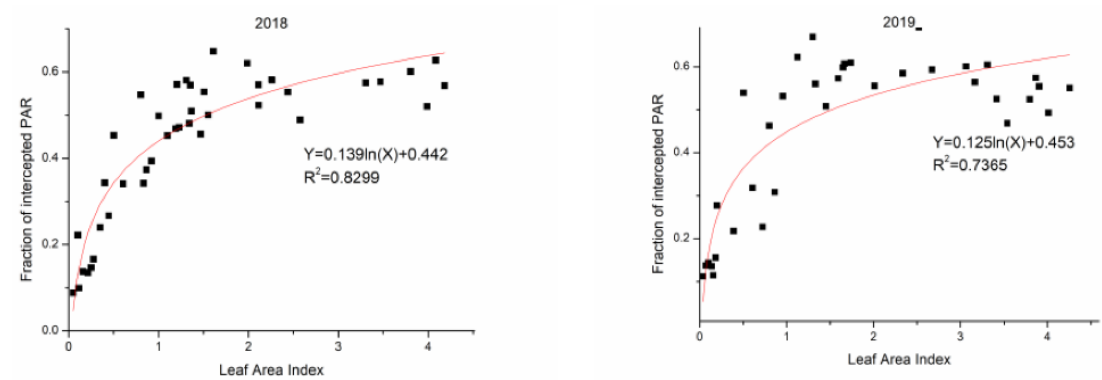

Figure 13. Relationships and fitted models for the iPAR and leaf area index (LAI) per plant in 2018 and 2019.
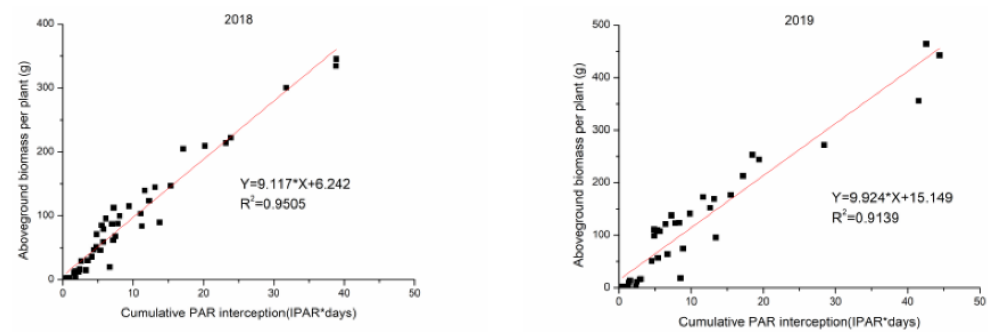

Figure 14. Relationships and fitted models for the cumulative PAR interception and cotton plant aboveground biomass in 2018 and 2019.
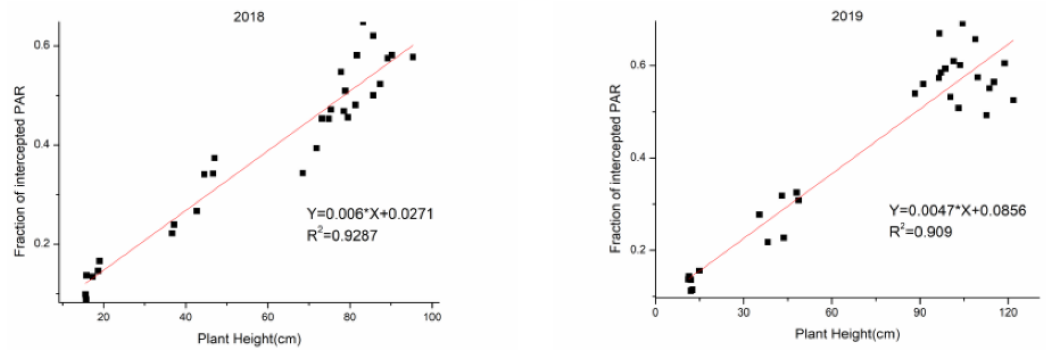

Figure 15. Relationships and fitted models for iPAR and plant height in 2018 and 2019.

\subsection{Yield}

In both years, the D5 plant density resulted in the highest production of seed cotton, followed by the highest plant density (D6). The highest seed cotton yields were 4232.2 and $4351.5 \mathrm{~kg} \mathrm{ha}^{-1}$ in 2018 and 2019, respectively, which were $14.9 \%, 15.0 \%, 25.6 \%, 37.4 \%$ and $54.5 \%$ higher than those in D6, D4, D3, D2 and D1, respectively, in 2018, and 4.3\%, 6.2\%, 7.3\%, 15.5\% and 31.9\% higher than those in D6, D4, D3, D2 and D1, respectively, in 2019. The highest lint yields were 1545.3 and $1789.5 \mathrm{~kg} \mathrm{ha}^{-1}$, produced at D5, in 2018 and 2019, respectively, which were $12.8 \%, 17.3 \%, 19.7 \%, 23.6 \%$ and $30.3 \%$ higher than those produced at D4, D6, D3, D2 and D1, respectively, in 2018, and 4.5\%, 8.5\%, 15.3\%, 23.2\% and 37.0\% 
higher than those produced at D6, D4, D3, D2 and D1, respectively, in 2019. The highest lint percentage (43.6\%) was recorded in D1, followed by D2, D3, D4 and D5 (Table 5).

Table 5. Comparison of seed cotton and lint yields at various planting densities during the cotton growing seasons in 2018 and 2019.

\begin{tabular}{cccc}
\hline Treatment & Seed Cotton Yield $\left(\mathbf{k g ~ h a}^{-\mathbf{1})}\right.$ & Lint Yield $\left.\mathbf{( k g ~ h a} \mathbf{~}^{-\mathbf{1}}\right)$ & Lint Percentage (\%) \\
\hline Year 2018 & & & \\
D1 & $2730.9 \pm 96.0 \mathrm{~d}$ & $1185.5 \pm 32.0 \mathrm{c}$ & $43.6 \pm 0.44 \mathrm{a}$ \\
D2 & $3080.5 \pm 66.0 \mathrm{~cd}$ & $1249.8 \pm 27.4 \mathrm{bc}$ & $41.3 \pm 0.58 \mathrm{a}$ \\
D3 & $3369.3 \pm 84.5 \mathrm{bc}$ & $1291.0 \pm 23.2 \mathrm{bc}$ & $38.4 \pm 0.79 \mathrm{a}$ \\
D4 & $3679.5 \pm 94.9 \mathrm{~b}$ & $1369.4 \pm 33.1 \mathrm{~b}$ & $37.3 \pm 0.28 \mathrm{a}$ \\
D5 & $4232.2 \pm 116.1 \mathrm{a}$ & $1545.3 \pm 28.2 \mathrm{a}$ & $36.5 \pm 0.37 \mathrm{a}$ \\
D6 & $3682.2 \pm 67.5 \mathrm{~b}$ & $1316.8 \pm 26.8 \mathrm{bc}$ & $35.8 \pm 0.62 \mathrm{a}$ \\
\hline Year 2019 & & & \\
D1 & $3299.1 \pm 128.2 \mathrm{~d}$ & $1306.4 \pm 41.8 \mathrm{~d}$ & $39.3 \pm 1.07 \mathrm{a}$ \\
D2 & $3767.0 \pm 68.4 \mathrm{c}$ & $1451.9 \pm 23.3 \mathrm{~cd}$ & $38.6 \pm 1.15 \mathrm{a}$ \\
D3 & $4054.6 \pm 20.2 \mathrm{~b}$ & $1552.7 \pm 10.4 \mathrm{bc}$ & $39.0 \pm 1.10 \mathrm{a}$ \\
D4 & $4095.8 \pm 72.8 \mathrm{ab}$ & $1649.4 \pm 28.2 \mathrm{ab}$ & $39.1 \pm 1.24 \mathrm{a}$ \\
D5 & $4351.5 \pm 159.0 \mathrm{a}$ & $1789.5 \pm 32.5 \mathrm{a}$ & $39.1 \pm 1.31 \mathrm{a}$ \\
D6 & $4172.3 \pm 105.4 \mathrm{ab}$ & $1712.8 \pm 17.3 \mathrm{ab}$ & $38.7 \pm 1.14 \mathrm{a}$ \\
\hline
\end{tabular}

Means followed by the same letters within the same category are statistically similar according to Duncan's multiple range test at $p<0.05$.

The spatial distribution of cotton yield varied according to the different plant densities and at the different positions (Figure 16). With the exception of D6, a high plant density resulted in a high number of nodes with cotton bolls. As cotton plant density increased, the order of the number of nodes with cotton bolls was D1 > D2 > D3 > D6 > D4 > D5, and the distribution of cotton bolls was concentrated at the vertical center of the cotton plants. In terms of the horizontal position, as cotton density increased, the distribution of cotton bolls was concentrated toward the inner side of the cotton plants.

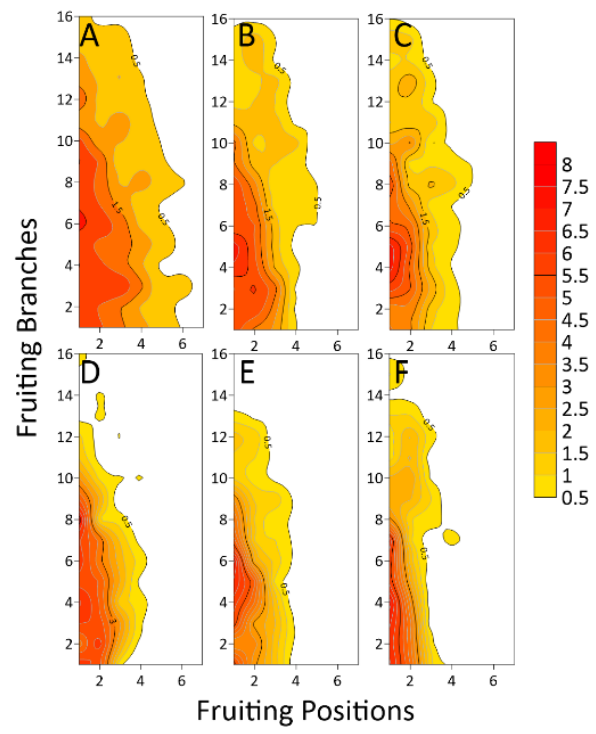

Figure 16. Spatial distribution of average cotton yield at different planting densities averaged across in 2018 and 2019. (A) D1; (B) D2; (C) D3; (D) D4; (E) D5; (F) D6.

\section{Discussion}

Spatial distribution of light interception by cotton growing at different densities is of great importance, as light interception directly affects photosynthesis and influences biomass and yield [31]. The traditional method to estimate the vertical direction of light 
interception in the crop canopy is Beer's law [32], however, leaf angle and leaf curve are needed to simulate the model to calculate PAR distribution of different height of the canopies and contains a series of mathematical functions which are difficult to measure and calculate [33]. The 3-D structure models are also widely used to calculate the light interceptions of crop canopies, which need a variety of measurement and data analysis [34]. This study presents the spatial grid method to identify stable measurement points in the cotton canopy between two cotton rows, which established a spatial grid perpendicular to the cotton plants, and focused on the comparison of light interception by cotton plants. By calculating the fraction of intercepted PAR (iPAR), PAR reflectance (rPAR) and PAR transmittance (tPAR) at each measurement point in the cotton canopy according to Tang's method and the extension of Simpson's 3/8 rule, multiple grid files representing different densities can be combined into one file to analyze differences in light interception by different cotton plant populations.

During the vigorous period of cotton growth and development, one of the most important factors of cotton growth was density [35], which showed obvious regional patterns and a high degree of spatial autocorrelation [36]. The plants growing at higher densities experienced greater competition than those at the lower densities with smaller cotton plants, fewer buds and bolls and lower productivity [37], which demonstrated the effect of spatial correlation between crop growth and yield. In both years, the D5 plant density with the highest seed cotton yield and lint yield, followed by D6, D4, D3, D2 and D1. The number of fruit branches per plant and the number of bolls per plant decreased with the increase of density. With the increase of density, the proportion of upper boll, middle boll and inner boll increased, and the proportion of lower boll and outer boll decreased [38].

The distribution of light interception at different canopy positions is spatially variable. Additionally, when canopy height increased, light interception decreased, it might be affected by the elevation of the sun or the diffuse radiation received at the lower layers of canopy [39-41]. In the horizontal direction iPAR values were greater near the cotton rows than at the inter-row of the canopy. According to Xue's research, light interception of horizonal layers was not significantly different at the late stage of growth period, and in the early stage showed obvious difference of light interception among different densities, which increased light-use efficiency [42]. In this study, the distribution and variation in light interception during the flowering stage were analyzed, and the result showed that light interception among six different cotton densities showed significant differences in vertical direction, which obviously differed at canopy heights below $80 \mathrm{~cm}$ near the side of the cotton row and was mainly affected by the upper position of the canopy [43].

The competition between plants at different densities influenced the number and size of the leaves and influenced the canopy size, which affected the iPAR and yield [44]. In the whole cotton population, LAI increased when plant densities increased, however, the leaf area of a single plant was significantly higher in the low densities, which may be a reason why the cotton yield of D6 was high but slightly lower than D5, for the excessive leaf area may cause serious shedding in the field and leaf abscission, which affect light interception. If leaf area is small, though the light conditions are satisfied, the total photosynthetic products cannot meet the needs of boll growth, both situations lead to low yield of cotton [45]. A highly significant relationship was found between iPAR and leaf area, which is in strong agreement with previous studies [14,24,31].

Light is one of the original sources of energy which directly affect crop growth. The accumulation of biomass was significantly related to radiation-use efficiency in different crops [46-49]. In this study, higher densities showed higher aboveground biomass and yield in population, which may be because a higher density of plants with greater light interception presents a higher speed and longer period of fast biomass accumulation, for single plant the D1 density of plant was significantly higher than others, the reason was that the plants in low densities have less competition which each other, and each plant can receive enough light interception for growth, but the whole plant population was less 
competitive than the high-density ones. The trend of aboveground biomass accumulation followed the same rules as in Khan's study [30], and the aboveground biomass of a single plant and the whole population growing at different densities were both linearly related to cumulative iPAR $[14,41]$. However, low plant densities present lower cotton productivity, that may be because early leaf senescence may cause low light-use efficiency in a population, which furthermore reduces boll weight [50].

The plant can also increase light interception by increasing plant height [51]. It was shown that plant height had a linear relationship with iPAR, which was because plant height may directly affect light interception and changes in the wind field within the cotton population, and, furthermore, affect the shedding area and photosynthesis at the bottom of crop canopies [52].

Canopy structure may also play an important role by directly affecting PAR and photosynthesis, with a further influence on light interception by the canopy and plant yield [53-55]. With increasing cotton plant density, cotton leaf area increased, while plant height decreased, further improving the canopy structure and increasing biomass accumulation [56].

Conclusively, the cotton population with a higher density $\left(8.7\right.$ plants $\left.\mathrm{m}^{-2}\right)$ performed best at light interception, with the highest light-use efficiency and the highest yield.

\section{Conclusions}

Light is of great importance during the cotton growing period, and for the different densities of cotton plants, it was necessary to study the spatial distribution of light interception. The results of this study showed that (i) iPAR of the whole cotton canopy was higher at a high cotton plant density than at a lower density, and in the horizontal direction, differences in light interception were obvious at canopy heights below $80 \mathrm{~cm}$ near the side of the cotton row, (ii) LAI and aboveground biomass were obviously correlated with light interception. (iii) The cotton population with a higher density $\left(8.7\right.$ plants $\left.\mathrm{m}^{-2}\right)$ performed best at the light interception, with the highest yield. The results will provide a significant basis by which to improve the management of light and canopy architecture.

Author Contributions: Y.L. (Yabing Li) and Y.H. designed the experiment. W.D., B.Y., S.X., M.X. and J.A. conducted the experiment. Y.L. (Yaping Lei), F.X., L.F., X.L. and G.W. helped and provided useful suggestions during the experiment. H.C. and X.Z. processed and analyzed data and wrote the first draft. Y.L. (Yabing Li), L.F. and Z.W. revised and edited the manuscript. All authors have read and agreed to the published version of the manuscript.

Funding: We are thankful for the financial support by National Natural Foundation of China (31371561). The funder had no role in design, data collection and decision to publish or preparation of manuscript.

Institutional Review Board Statement: Not applicable.

Informed Consent Statement: Not applicable.

Data Availability Statement: Not applicable.

Acknowledgments: We highly acknowledge the help of technicians of the research station from the institute of cotton research Chinese Academy of Agricultural Sciences.

Conflicts of Interest: The authors declare no conflict of interests.

\section{References}

1. Lu, X.; Jia, X.; Niu, J. The present situation and prospects of cotton industry development in China. Sci. Agric. Sin. 2018, 51, 26-36.

2. Chen, M. Research on issues related to the development of China's cotton industry-report at the 2014 annual meeting of China cotton association. China Cotton 2014, 41, 38-43.

3. Mao, S.; Li, Y. Report on China's Cotton Production Prosperity 2017; China Agriculture Press: Beijing, China, 2018.

4. Zhang, B.; Bian, X. Evaluation of compresive benefits of smart agriculture in Heilongjiang province based on AHP. Chin. J. Agric. Resour. Reg. Plan 2019, 40, 109-115. 
5. Mao, S. The modernization of cotton cultivation technology in China also focuses on the research related to cotton cultivation in the 12th Five-Year Plan. China Cotton 2010, 37, 2-5.

6. Dai, J.; Dong, H. Field Crops Research Intensive cotton farming technologies in China: Achievements, challenges and countermeasures. Field Crops Res. 2014, 155, 99-110. [CrossRef]

7. Mao, S.; Li, Y.; Dong, H.; Bie, S.; Lin, Y.; Dong, H.; Tian, L.; Chen, D.; Ma, Q.; Ma, X.; et al. Institute of Cotton Research of CAAS. In Cotton Cultivation in China; Shanghai Scientific and Technical Publisher: Shanghai, China, 2013; pp. $123-124$.

8. Zhang, W.; Gou, L.; Li, M. Studies on The Relationship Between Canopy Apparent Photosynthesis Rate and Yield in Cotton in North Xinjiang. Cotton Sci. 1999, 11, 185-190.

9. McCree, K.J. Photosynthetically Active Radiation. Physiological Plant Ecology I; Springer: Berlin/Heidelberg, Germany, 1981.

10. McCree, K.J. Test of current definitions of photosynthetically active radiation against leaf photosynthesis data. Agric. Meteorol. 1972, 10, 443-453. [CrossRef]

11. Gent, M.P.N. Canopy light interception, gas exchange, and biomass in reduced height isolines of winter wheat. Crop. Sci. 1995, 35, 1636-1642. [CrossRef]

12. Zhang, L.Z.; Van der Werf, W.; Bastiaans, L.; Zhang, S.; Li, B.; Spiertz, J.H.J. Light interception and utilization in relay intercrops of wheat and cotton. Field Crops Res. 2008, 107, 29-42. [CrossRef]

13. Trouwborst, G.; Oosterkamp, J.; Hogewoning, S.W.; Harbinson, J.; Van Ieperen, W. The responses of light interception, photosynthesis and fruit yield of cucumber to LED-lighting within the canopy. Physiol. Plant. 2010, 138, 289-300. [CrossRef]

14. Zhi, X.; Han, Y.; Xing, F.; Lei, Y.; Wang, G.; Feng, L.; Yang, B.; Wang, Z.; Li, X.; Xiong, S. How do cotton light interception and carbohydrate partitioning respond to cropping systems including monoculture, intercropping with wheat, and direct-seeding after wheat? PLoS ONE 2019, 14, e0217243. [CrossRef] [PubMed]

15. Louarn, G.; Lecoeur, J.; Lebon, E. A three-dimensional statistical reconstruction model of grapevine (Vitis vinifera) simulating canopy structure variability within and between cultivar/training system pairs. Ann. Bot. 2008, 101, 1167-1184. [CrossRef] [PubMed]

16. Vargas, L.A.; Andersen, M.N.; Jensen, C.R.; Jorgensen, U. Estimation of leaf area index, light interception and biomass accumulation of Miscanthus sinensis 'Goliath' from radiation measurements. Biomass Bioenergy 2002, 22, 1-14. [CrossRef]

17. Heitholt, J.J.; Pettigrew, W.T.; Meredith, W.R. Light Interception and Lint Yield of Narrow-Row Cotton. Crop. Sci. 1992, 32, 728-733. [CrossRef]

18. Wells, R. Soybean growth response to plant density: Relationships among canopy photosynthesis, leaf area, and light interception. Crop. Sci. 1991, 31, 755-761. [CrossRef]

19. Goudriaan, J.; Monteith, J.L. A mathematical function for crop growth based on light interception and leaf area expansion. Ann. Bot. 1990, 66, 695-701. [CrossRef]

20. Maddonni, G.A.; Otegui, M.E. Leaf area, light interception, and crop development in maize. Field Crops Res. 1996, 48, 81-87. [CrossRef]

21. Du, X.; Chen, B.; Shen, T.; Zhang, Y.; Zhou, Z. Effect of cropping system on radiation use efficiency in double-cropped wheatcotton. Field Crops Res. 2015, 170, 21-31. [CrossRef]

22. Chapepa, B.; Mudada, N.; Mapuranga, R. The impact of plant density and spatial arrangement on light interception on cotton crop and seed cotton yield: An overview. J. Cotton Res. 2020, 3, 1-6. [CrossRef]

23. Bhattacharya, A. Changing Climate and Resource Use Efficiency in Plants; Academic Press: Cambridge, MA, USA, 2018.

24. Zhi, X.; Han, Y.; Mao, S.; Wang, G.; Feng, L.; Yang, B.; Fan, Z.; Du, W.; Lu, J.; Li, Y. Light spatial distribution in the canopy and crop development in cotton. PLoS ONE 2014, 9, e113409. [CrossRef]

25. Vos, J.; Evers, J.B.; Buck-Sorlin, G.H.; Andrieu, B.; Chelle, M.; de Visser, P.H.B. Functional-structural plant modelling: A new versatile tool in crop science. J. Exp. Bot. 2010, 61, 2101-2115. [PubMed]

26. Rey, H.; Dauzat, J.; Chenu, K.; Barczi, J.F.; Dosio, G.A.A.; Lecoeur, J. Using a 3-D virtual sunflower to simulate light capture at organ, plant and plot levels: Contribution of organ interception, impact of heliotropism and analysis of genotypic differences. Ann. Bot. 2008, 101, 1139-1151. [CrossRef] [PubMed]

27. Gu, S.; Evers, J.B.; Zhang, L.; Mao, L.; Zhang, S.; Zhao, X.; Liu, S.; van der Werf, W.; Li, Z. Modelling the structural response of cotton plants to mepiquat chloride and population density. Ann. Bot. 2014, 114, 877-887. [CrossRef]

28. Mao, L.; Zhang, L.; Evers, J.B.; Henke, M.; van der Werf, W.; Liu, S.; Zhang, S.; Zhao, X.; Wang, B.; Li, Z. Identification of plant configurations maximizing radiation capture in relay strip cotton using a functional-structural plant model. Field Crops Res. 2016, 187, 1-11. [CrossRef]

29. Tang, Q. Studys on Canopy Photosynthesis Characteristic of Cotton with Different Leaf-Type; Shihezi University: Shihezi, China, 2014.

30. Khan, N.; Xing, F.; Feng, L.; Wang, Z.; Xin, M.; Xiong, S.; Wang, G.; Chen, H.; Du, W.; Li, Y. Comparative Yield, Fiber Quality and Dry Matter Production of Cotton Planted at Various Densities under Equidistant Row Arrangement. Agronomy 2020, 10, 232. [CrossRef]

31. Xing, F.; Han, Y.; Feng, L.; Zhi, X.; Wang, G.; Yang, B.; Fan, Z.; Lei, Y.; Du, W.; Wang, Z.; et al. Genotypic variation in spatiotemporal distribution of canopy light interception in relation to yield formation in cotton. J. Cotton Res. 2018, 1, 13. [CrossRef]

32. Monsi, M.; Saeki, T. Über den Lichtfaktor in den Pflanzengesellschaften und seine Bedeutung für die Stoffproduktion. Jpn. J. Bot. 1953, 14, 22-52. 
33. Zhang, W.Y.; Tang, L.; Yang, X.; Liu, L.L.; Cao, W.X.; Zhu, Y. A simulation model for predicting canopy structure and light distribution in wheat. Eur. J. Agron. 2015, 67, 1-11. [CrossRef]

34. Cao, W.X. Digital Farming Technology; Science Press: Beijing, China, 2018.

35. Li, Y.; Mao, S.; Wang, X.; Han, Y.; Wang, G.; Fan, Z.; Zhu, Q. Cotton Growth Condition Spatial Variance Analysis Based on Geo-statistics. Cotton Sci. 2007, 19, 214-219.

36. Liu, Y.; Pan, X. The Analysis on Dominant Provinces of Cotton Production in China. Chin. Agric. Sci. Bull. 2006, 22, 360-364.

37. Wang, Y.; Cui, X.; Pan, X.; Pan, S. Study on the effect of competition among cotton plants on light energy utilization and growth and development. China Cotton 1999, 08, 3-5.

38. Li, F. Study on the spatial distribution of cotton bells of different planting densities in SCRC28. Cotton Sci. 2012, 34, 25-27.

39. Leuchner, M.; Hertel, C.; Menzel, A. Spatial variability of photosyntheticallyactive radiation in European beech and Norway spruce. Agric. For. Meteorol. 2011, 151, 1226-1232. [CrossRef]

40. Sarlikioti, V.; de Visser, P.H.; Marcelis, L.F. Exploring the spatial distributionof light interception and photosynthesis of canopies by means of afunctional-structural plant model. Ann. Bot. 2011, 107, 875-883. [CrossRef]

41. Zhi, X.; Han, Y.; Wang, G.; Feng, L.; Yang, B.; Fan, Z.; Du, W.; Lei, Y.; Mao, S.; Li, Y. Changes to the PAR Spatial Distribution, Biomass, and Fiber Quality in Response to Plant Densities. Cotton Sci. 2017, 29, 365-373.

42. Xue, H.; Han, Y.; Li, Y.; Wang, G.; Feng, L.; Fan, Z.; Du, W.; Yang, B.; Cao, C.; Mao, S. Spatial distribution of light interception by different plant population densities and its relationship with yield. Field Crops Res. 2015, 184, 17-27. [CrossRef]

43. Han, C.; Wei, S. The study of canopy characteristics of high-yielding groups in rice and their relationship with yield. Liaoning Agric. Sci. 1996, 3, 24-27.

44. Bai, Z. Study on light interception and biomass production of different cotton cultivars. PLoS ONE 2016, 11, e0156335. [CrossRef]

45. Shi, W. Effects of Plant Densities in Cotton (Gossypium hirsutum L.) Dry Matter Accumulation and Distribution, Yield and Fiber Quality; Nanjing Agricultural University: Nanjing, China, 2012.

46. Kiniry, J.R.; Jones, C.A.; O'toole, J.C.; Blanchet, R.; Cabelguenne, M.; Spanel, D.A. Radiation-use efficiency in biomass accumulation prior to grain-filling for five grain-crop species. Field Crops Res. 1989, 20, 51-64. [CrossRef]

47. Flénet, F.; Kiniry, J.R.; Board, J.E.; Westgate, M.E.; Reicosky, D.C. Rows pacing effects on light extinction coefficients of corn, sorghum soybean and sunflower. Agron. J. 1996, 88, 185-190. [CrossRef]

48. Kiniry, J.R.; Williams, J.R.; Vanderlip, R.L.; Atwood, J.D.; Reicosky, D.C.; Mulliken, J.; Cox, W.J.; Mascagni, H.J., Jr.; Hollinger, S.E.; Wiebold, W.J. Evaluation of two maize models for nine U.S. locations. Agron. J. 1997, 89, 421-426. [CrossRef]

49. Connor, D.J.; Fereres, E. A dynamic model of crop growth and partitioning of biomass. Field Crops Res. 1999, 63, 139-157. [CrossRef]

50. Dai, J.; Li, W.; Tang, W.; Zhang, D.; Li, Z.; Lu, H.; Eneji, A.E.; Dong, H. Manipulation of dry matter accumulation and partitioning with plant density in relation to yield stability of cotton under intensive management. Field Crops Res. 2015, 180, 207-215. [CrossRef]

51. Francescangeli, N.; Sangiacomo, M.A.; Martí, H. Effects of plant density in broccoli on yield and radiation use efficiency. Sci. Hortic. 2006, 110, 135-143. [CrossRef]

52. Cheng, G.; Sun, H.; Zhang, Y.; Liu, L.; Wang, M.; Li, C. Effects of canopy structure on photosynthesis and yield in cotton. J. Agric. Univ. Hebei 2015, 38, 1-7.

53. Lv, X.; Wang, K.; Liu, J.; Chu, G.; Yang, Y.; Dun, J.; Yao, C.; Zhou, F. An Analysis of Characters on Wheat/Corn Compound Canopy Structure. J. Shihezi Univ. (Nat. Sci.) 2001, 5, 120-122.

54. Khan, N.; Han, Y.; Xing, F.; Feng, L.; Wang, Z.; Wang, G.; Yang, B.; Fan, Z.; Lei, Y.; Xiong, S.; et al. Plant Density Influences Reproductive Growth, Lint Yield and Boll Spatial Distribution of Cotton. Agronomy 2020, 10, 14. [CrossRef]

55. Liu, F. Experimental and Mathematical Model of Rice Canopy Structure and Dry Matter Production under Controlled Irrigation; Hehai University: Nanjing, China, 2005.

56. Zhang, D. Effect of Cotton Plant Densities on Light Distribution and LUE of Jujube-Cotton Intercropped Systems; Shihezi University: Shihezi, China, 2014. 